\title{
EVIDENCE OF PHYSICO-CHEMICAL AND ISOTOPIC MODIFICATIONS IN ARCHAEOLOGICAL BONES DURING CONTROLLED ACID ETCHING
}

\author{
V. BALTER,,${ }^{1,4 *}$ J.-F. SALIÈGE, ${ }^{2}$ H. BOCHERENS ${ }^{3} \dagger$ and A. PERSON ${ }^{1}$ \\ ${ }^{1}$ CNRS-UP6 FRE 2400 'Laboratoire de Géologie des Bassins Sédimentaires', Université Pierre et Marie \\ Curie, CP 116, 4 Place Jussieu, 75252 Paris Cedex 05, France \\ ${ }^{2}$ L.O.D.Y.C. Université Pierre et Marie Curie, CP 100, 4 Place Jussieu, 75252 Paris Cedex 05, France \\ ${ }^{3}$ CNRS-INRA UMR 7618 'Laboratoire de Biogéochimie Isotopique', Université Pierre et Marie Curie, \\ CP 120, 4 Place Jussieu, 75252 Paris Cedex 05, France \\ ${ }^{4}$ Laboratoire d'Anthropologie des Populations du Passé, Université Bordeaux I, \\ Avenue des Facultés, 33405 Talence Cedex, France
}

It has been repeatedly shown that palaeoecological inferences from the elemental and isotopic content of carbonate hydroxylapatite of fossil teeth and bones are unrecoverable without removing diagenetic overprinting by chemical pretreatments. Such pretreatments may in turn cause modification of the biogenic signature. In this paper, we focus upon optimal removal of Ca-bearing carbonates (mainly calcite). In order to control the progress with time of calcite dissolution, we perform leaching under vacuum, and we monitor the evolution of the $\mathrm{pH}, \mathrm{pCO}_{2}, \delta^{13} \mathrm{C}$ of released $\mathrm{CO}_{2}, \% \mathrm{C}, \delta^{13} \mathrm{C}$ and $\delta^{18} \mathrm{O}$ of the remaining mineral. For a set of different Quaternary bones and teeth, mass and isotopic balances indicate that $1 \mathrm{~h}$ at most is necessary for complete dissolution of calcite with an optimal conservation of carbonate hydroxylapatite. Long-lasting experiments lead to ${ }^{18} \mathrm{O} /{ }^{16} \mathrm{O}$ fractionation of hydroxylapatite carbonates.

KEYWORDS: QUATERNARY BONES AND TEETH, CARBONATE HYDROXYLAPATITE, CARBON AND OXYGEN ISOTOPES, PALAEOECOLOGY, RADIOCARBON, DIAGENESIS, CHEMICAL PRETREATMENT

\section{INTRODUCTION}

The inorganic phase of bone and teeth (enamel and dentine) is composed of carbonate hydroxylapatite (HAP), which mineralizes in relation to environmental conditions (mainly diet and climate) that can be depicted using isotopic and elemental proxies. These tools have been widely used to reconstruct past environments and behaviour with fossil HAP (see, e.g., van der Merwe 1982; Sponheimer and Lee-Thorp 1999 for ${ }^{13} \mathrm{C} /{ }^{12} \mathrm{C}$ : e.g., Longinelli 1984; MacFadden et al. 1999 for ${ }^{18} \mathrm{O} /{ }^{16} \mathrm{O}$ : e.g., Lambert and Weydert-Homeyer, 1993; Burton et al. 1999 for $\mathrm{Sr} / \mathrm{Ca}$ and $\mathrm{Ba} / \mathrm{Ca}$ ). To be successful, these approaches must take into account that post mortem modifications, due to burial, are a priori effective (Kohn et al. 1999). Authigenic solid solutions of Ca-bearing carbonates (mainly calcite) are frequently present in fossil bones and teeth. Because of its composition, calcite represents one of the most disturbing diagenetic compounds

* Present address: UMR CNRS-Lyon I 'PaléoEnvironnement et PaléobioSphère', Université Claude Bernard, Campus de la Doua, Bâtiment Géode. Bd du 11/11/1918, 69622 Villeurbanne Cedex, France.

† Present address: CNRS-UM2 UMR 554 'Laboratoire de Paléontologie', Université Montpellier 2, Place Eugène Bataillon, case courrier 064 F-34095 Montpellier Cedex 5, France.

(c) University of Oxford, 2002 
by yielding exogenous substrates for carbonate isotopes, radiocarbon and $\mathrm{Sr} / \mathrm{Ca}$ analysis. Many authors have proposed chemical pretreatment protocols to remove such compounds (Sillen and LeGeros 1991; Hedges et al. 1995; Saliège et al. 1995; Koch et al. 1997), but no general agreement has ever been reached, notably regarding the duration of leaching experiments. This is of particular importance because it has been demonstrated that pretreatments may dissolve the most soluble HAP, a fraction considered to be less modified by diagenesis (Sillen and LeGeros 1991). Since the solubility of calcite $\left(K_{\text {s calcite }} \cong 10^{-8}\right)$ is ten orders of magnitude greater than that of HAP $\left(K_{\mathrm{s} \mathrm{HAP}} \cong 10^{-60}\right)$, total dissolution of calcite must be completed rapidly. The acid etching has been prolonged by several authors for a long time, leading to unavoidable partial dissolution and/or recrystallization of HAP. Not surprisingly, different studies have demonstrated that the quality of pretreatment may interfere with the values and reproducibility of the results (Lee-Thorp and van der Merwe 1991; Price et al. 1992; Koch et al. 1997). In isotopic chemistry, partial reactions lead to a relative isotopic enrichment of the remaining phase. Thus the carbon and oxygen isotopic ratios during HAP partial dissolution might be influenced by this kinetic rule, yielding inappropriate results for palaeobiological investigations. We performed acid etching under vacuum for a set of archaeological and palaeontological bones and teeth in order to (1) accelerate the kinetics of the calcite dissolution (and thus minimize the HAP contact with acid) and (2) control the progress of the reaction with time by mass and isotopic balance.

\section{MATERIALS}

Several archaeological bones that had completely lost their organic matter (because it would have complicated interpretations) were selected. The nitrogen content $(\% \mathrm{~N})$ was measured to assess the quantity of the remaining collagen. Fresh bone typically contains about 4-5\% of nitrogen (Person et al. 1995). Iwelen and Hili (samples Hili 1\&3) are two Neolithic ( $\approx 3 \mathrm{ka} \mathrm{\textrm {BP } )}$ sites from Niger and Saudi Arabia. The bones from Iwelen came from sealed tombs and no secondary carbonates were detectable (Saliège et al. 1995): \% $\mathrm{N}$ is 0.11 for Iwelen. Azé and Saint-Césaire are a middle $(\approx 300 \mathrm{ka} \mathrm{BP})$ and an upper (35 ka вР) Palaeolithic French cave, respectively: \% $\mathrm{N}$ is $0.05 \%$ for Azé and $0.2 \%$ for Saint-Césaire. Enamel HAP is widely used in palaeoecological studies due to its resistance to diagenetic modification. One sample of palaeontological elephant enamel (Chad, $\approx 1 \mathrm{Ma}$, denoted Enamel 1) was selected in addition to a modern one (Enamel 2, cow sample). The latter serves as a control for the HAP dissolution. Since $\% \mathrm{~N}$ is generally lower than $1 \%$ in enamel (Carlson 1990), we did not perform \%N analysis for the enamel samples.

\section{Methodology}

The bone and enamel samples were ground manually in an agate mortar and sieved at $60 \mu \mathrm{m}$. They were soaked in doubly distilled water in the reaction vessel with a constant ratio of $1 \mathrm{~g} / 200 \mathrm{ml}$ (Fig. 1). The quality of the vacuum was visualized by the evolution of water degassing and controlled with a Pirani gauge. Then, an exact volume of concentrated (100\%) acetic acid was added in the reaction vessel to obtain a $0.1 \mathrm{M}$ final concentration. This represents the exact quantity of $0.1 \mathrm{M}$ acetic acid necessary for the dissolution of a supposed $1 \mathrm{~g}$ pure calcite sample. Trap A is constantly maintained at $-80^{\circ} \mathrm{C}$ to avoid additive effects of water and acetic acid vapour strength. Moreover, following the process of the double distillation control, the partial pressure of $\mathrm{CO}_{2}\left(\mathrm{pCO}_{2}\right)$ was measured at $-80^{\circ} \mathrm{C}$ in trap $\mathrm{B}$ with the manometer (after trapping at $-180^{\circ} \mathrm{C}$ ) at different stages of the reaction. Finally, $\mathrm{CO}_{2}$ was trapped and cryogenically purified 


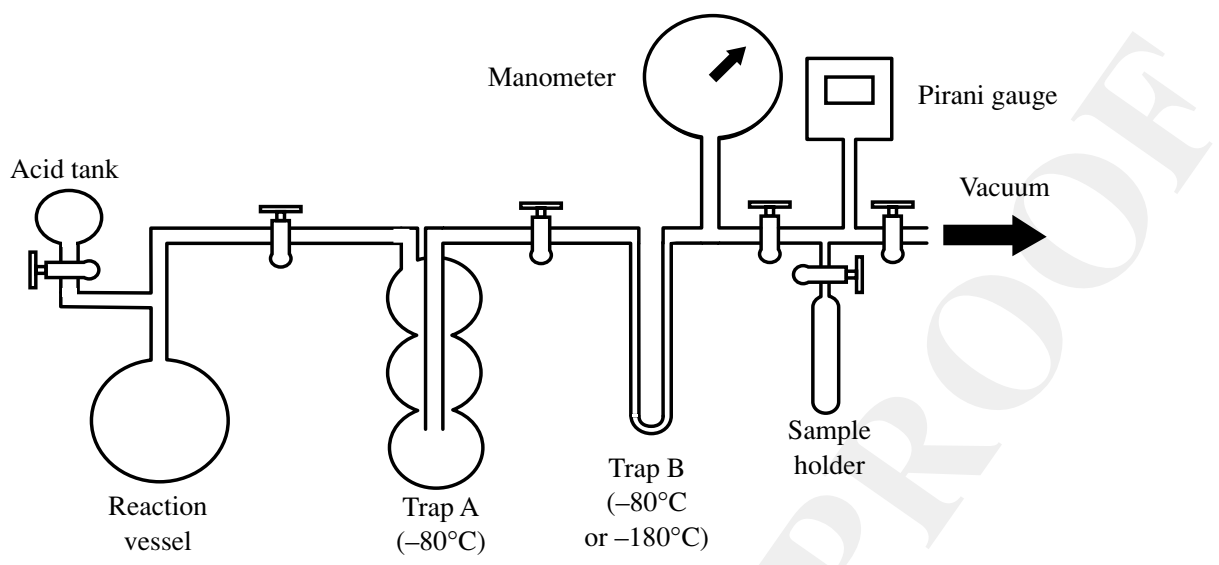

Figure 1 A sketch of the vacuum line apparatus used to extract and purify $\mathrm{CO}_{2}$.

twice before ${ }^{13} \mathrm{C} /{ }^{12} \mathrm{C}$ measurement. Simultaneously, the $\mathrm{pH}$ was measured and an aliquot of the remaining mineral was sampled, thoroughly washed with distilled water, dried overnight at room temperature, weighed and analysed for its ${ }^{13} \mathrm{C} /{ }^{12} \mathrm{C}$ and ${ }^{18} \mathrm{O} /{ }^{16} \mathrm{O}$ ratios. Stable isotope ratios were determined with a VG OPTIMA isotopic ratio mass spectrometer, coupled to an ISOCARB system. Oxygen and carbon are reported as $\delta=\left[\left(R_{\text {sample }}-R_{\text {standard }}\right)-1\right] \times 1000$, where $R={ }^{13} \mathrm{C} /{ }^{12} \mathrm{C}$ or ${ }^{18} \mathrm{O} /{ }^{16} \mathrm{O}$, and the standard is PDB. The standard deviation is typically $<0.1 \%$ for $\delta^{13} \mathrm{C}$ and $\delta^{18} \mathrm{O}$. The inorganic carbon content $(\% \mathrm{C})$ was evaluated by monitoring the $\mathrm{CO}_{2}$ generated from samples with the pressure transducer on the mass spectrometer. The crystallinity of HAP was determined by means of X-ray powder diffraction using a crystallinity index (CI) defined between $30^{\circ}$ and $38^{\circ} 2 \theta \mathrm{Cu}-\mathrm{K}_{\alpha}$ (Person et al. 1995).

\section{RESULTS AND DISCUSSION}

\section{The first hour (Fig. 2)}

The $\mathrm{pH}$ and cumulate $\mathrm{pCO}_{2}$ results indicate rapid evolution of the reaction during the first ten minutes, with an expected delay of $\mathrm{pCO}_{2}$ increasing in comparison to the $\mathrm{pH}$, due to liquid/gas phase transformation of $\mathrm{CO}_{2}$ (Fig. 2 (a)). Simultaneously, \% C may exhibit a rapid decrease (Hili 1 and Hili 3, Azé and Saint-Césaire) concomitant with calcite dissolution and $\mathrm{CO}_{2}$ release. Contrary to the previously noted absence of secondary $\mathrm{CO}_{3}$ in the bone sample from Iwelen (Saliège et al. 1995), which was determined on the basis of the variation of $\% \mathrm{C}, \mathrm{pCO}_{2}$ for this sample increases slightly during the first five minutes, whereas no sizeable variation occurs in $\%$ C. Since the precise crystallographic origin of this emitted $\mathrm{CO}_{2}$ could not be rigorously determined, the results suggest that measurement of $\mathrm{pCO}_{2}$ is a sensitive proxy of the presence of minute $\mathrm{CO}_{3}$ amounts in soluble crystallographic sites. The fossil enamel (Enamel 1) and the modern enamel (Enamel 2) show no additional $\mathrm{CO}_{3}$ in relation to the $\% \mathrm{C}$ variations with time (Fig. 2 (a)), but sample Enamel 2 exhibits an unexpected slight increase of $\mathrm{pCO}_{2}$, which is possibly related to the dissolution of adsorbed clusters of $\mathrm{CO}_{3}$. The evolution of $\delta^{18} \mathrm{O}$ and $\delta^{13} \mathrm{C}$ with time (Fig. 2 (b)) exhibits important variations for samples containing high initial and further decreasing \%C (i.e., the Hili 1, Hili 3, Azé and Saint-Césaire samples). At initial time $t_{0}$, the $\delta^{13} \mathrm{C}$ of these raw samples is influenced by the $\delta^{13} \mathrm{C}$ value of calcite (see 'Crystallinity control' below), which is in equilibrium with the atmospheric $\mathrm{CO}_{2}$ and thus theoretically close 
to $0 \%$ o. This implies that raw samples containing calcite have a systematically higher $\delta^{13} \mathrm{C}$ than etched samples. It follows that, for the high calcite content Hili 3 sample, the precise evolution of solid and $\mathrm{CO}_{2}$ released $\delta^{13} \mathrm{C}$ (Fig. 3). [[??]] The $\delta^{13} \mathrm{C}$ of the released $\mathrm{CO}_{2}$ reaches its most positive value in the first ten minutes. At the same time, $\mathrm{pCO}_{2}$ is initially high and tends to decrease as $\delta^{13} \mathrm{C}$ increases. This illustrates the rapid dissolution of a mineral phase characterized by a quite different $\delta^{13} \mathrm{C}$ value from the remaining mineral, whose values tend to decrease. We interpret this as the pure calcite $\delta^{13} \mathrm{C}$ value. All these trends indicate that calcite dissolution is characterized by rapid kinetics, and that it runs to completion in less than half an hour under conditions of dynamic vacuum.

\section{After the first hour (Figs 3 and 4)}

If we assume that the $\delta^{13} \mathrm{C}$ values for calcite and HAP in the Hili 3 sample are close to $-6 \%$ o and $-12 \%$ respectively, the evolution of the released $\mathrm{CO}_{2}$ after $1 \mathrm{~h}$ on a mixing line, progresses from the pure calcite end-member value towards the HAP end-member value: this trend illustrates HAP dissolution (Fig. 3). The $\delta^{13} \mathrm{C}$ values of the $\mathrm{CO}_{2}$ and the remaining mineral are similar at the end of the experiment, which indicates that HAP is dissolved without sizeable fractionation of the ${ }^{13} \mathrm{C} /{ }^{12} \mathrm{C}$ ratio. $\% \mathrm{C}$ decreases with time (Fig. 4) as expected according to the higher solubility of rich $\mathrm{CO}_{3}$-containing HAP (Sillen and LeGeros 1991). The isotopic kinetics predict a fractionation process between light and heavy isotopes in partial reactions (see, e.g., Faure 1986) with enrichment of the remaining phase. ${ }^{13} \mathrm{C} /{ }^{12} \mathrm{C}$ seems to be mostly insensitive to this process, because for all samples no $\delta^{13} \mathrm{C}$ variation is observed over time (Fig. 4). On the

(a)

Time (minutes)

Time (minutes)

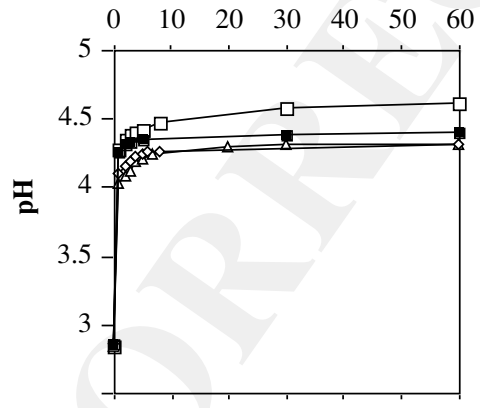

$\begin{array}{llllll}10 & 20 & 30 & 40 & 50 & 60\end{array}$
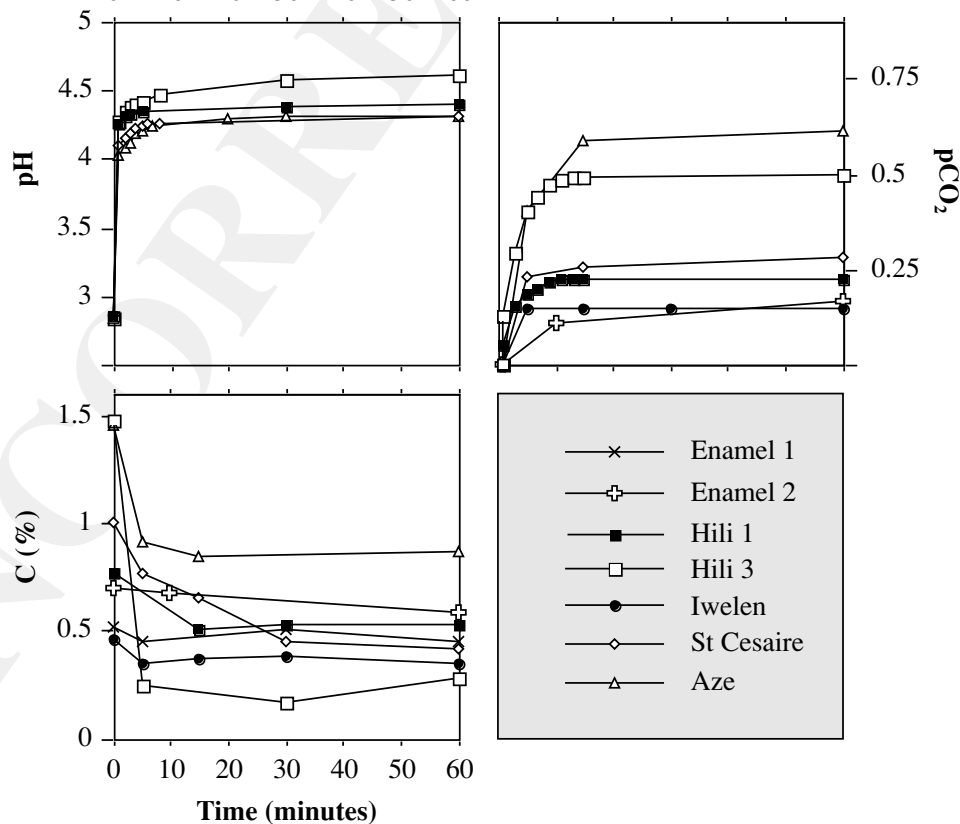

Figure 2 (a) Evolution in the first hour of $\mathrm{pH}, \mathrm{pCO}_{2}$ and $\mathrm{C}$. The units are $10^{5} \mathrm{~Pa}$ for $\mathrm{pCO} 2$ and $\%$ for $\mathrm{C}$. 
(b)

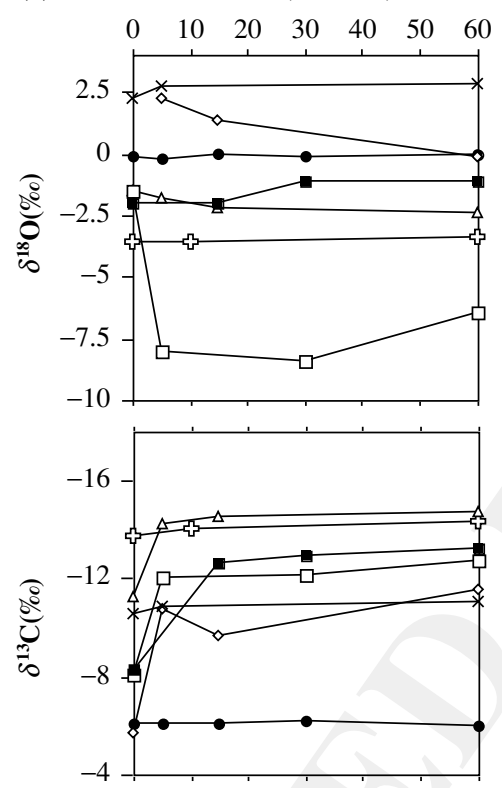

Time (minutes)

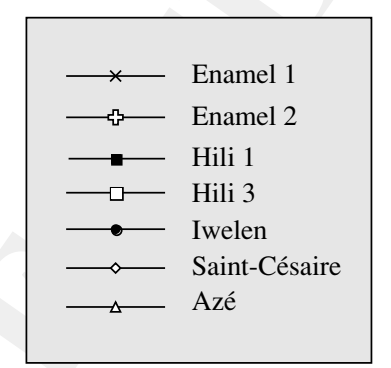

Figure 2 (b) The evolution in the first hour of the $\delta^{13} C$ and $\delta^{18} O$ of the remaining mineral. The units are \%o versus $P D B$.

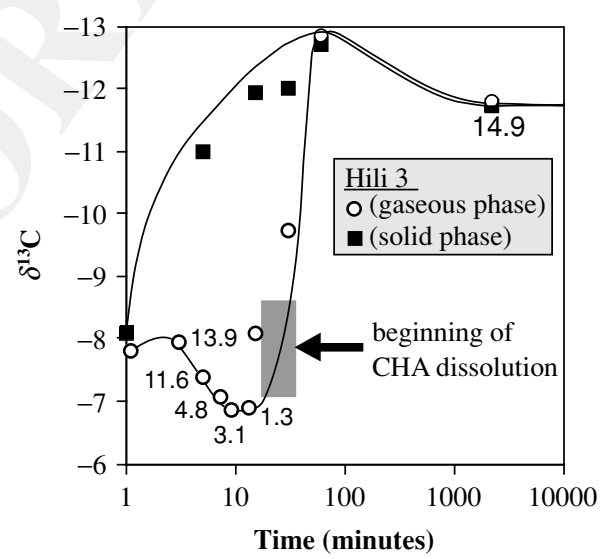

Figure 3 The evolution with time of the $\delta^{13} \mathrm{C}$ of the released $\mathrm{CO}_{2}$ during the etching reaction of the Hili 3 sample and the $\delta^{13} C$ of the remaining mineral. The units are \%o versus $P D B$. Added values indicate, in arbitrary units, the pressure of released $\mathrm{CO}_{2}$. 


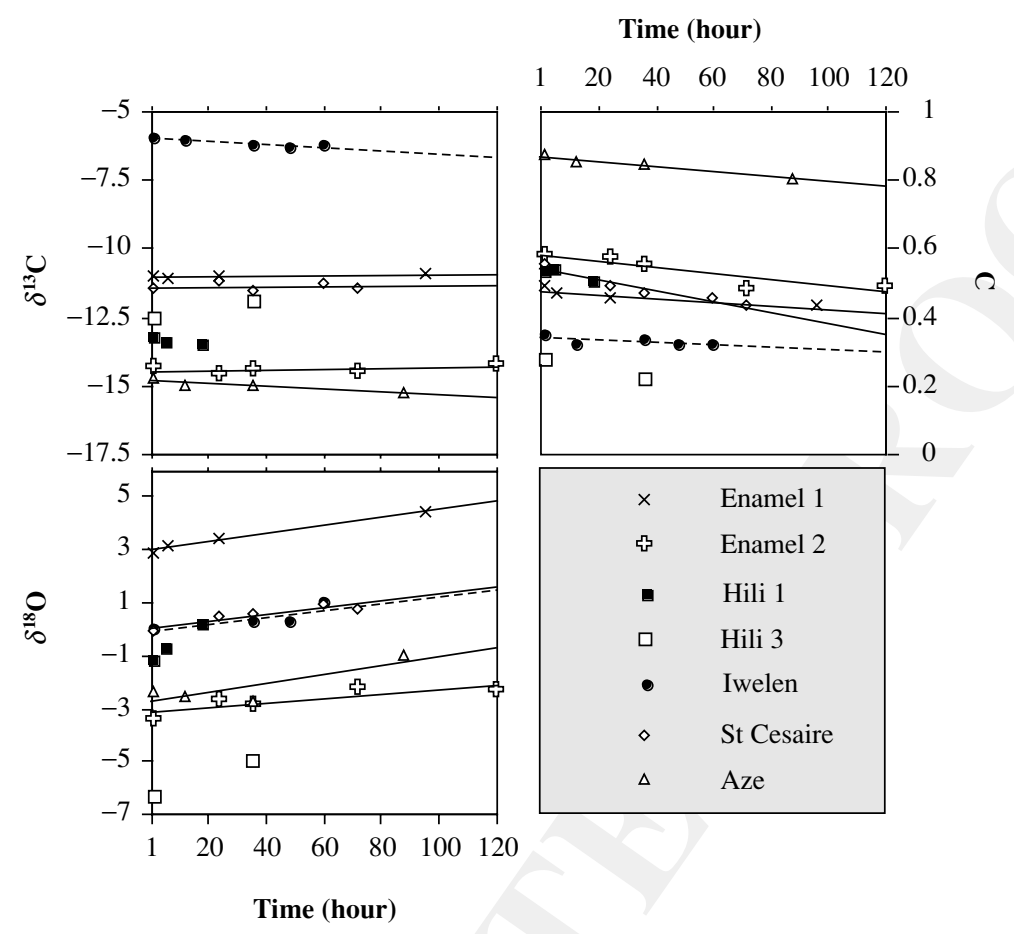

Figure 4 The evolution of the $C, \delta^{13} C$ and $? \delta^{18} O$ of the remaining mineral after the first hour. The units are \% for $C$ and \%o versus $P D B$ for $\delta^{13} C$ and $\delta^{18} O$. All $p H$ values remain acid at the end of the experiment.

other hand, ${ }^{18} \mathrm{O} /{ }^{16} \mathrm{O}$ is undoubtedly affected by a fractionation process that seems constant with time. Between $1 \mathrm{~h}$ and the end of the experiment, the increase in $\delta^{18} \mathrm{O}$ can reach $1 \%$ in some cases. Direct comparisons with experiments carried out under atmospheric conditions are not possible, but it is likely that long-lasting etching, even at a pH around 4.5 (Fig. 1), may lead to an uncertainty with regard to the isotopic carbonate oxygen.

\section{Crystallinity controls}

All samples display an HAP diffraction pattern that allows the measurement of the CI. Calcite diffraction peaks were present in the Hili 1 and 3, Azé and Saint-Césaire samples (Fig. 5). Ideally, chemical pretreatment should remove diagenetic compounds without altering the biogenic mineral. We performed in this sense a set of X-ray diffraction analysis measurements, to evaluate the possible modifications of the crystallographic characteristics of HAP. A decrease in \% C should correlate with an increase in crystallinity (Person et al. 1995). The studied samples (modern enamel and Azé) exhibit no crystallinity evolution after $1 \mathrm{~h}$ of etching. However, one day of experiment is sufficient to promote statistically significant modifications of HAP crystallites.

\section{CONCLUSIONS}

We have demonstrated that the vacuum technique is useful in pretreating archaeological bones and teeth, because it allows control of the progress of the reaction with time, and it reduces the 


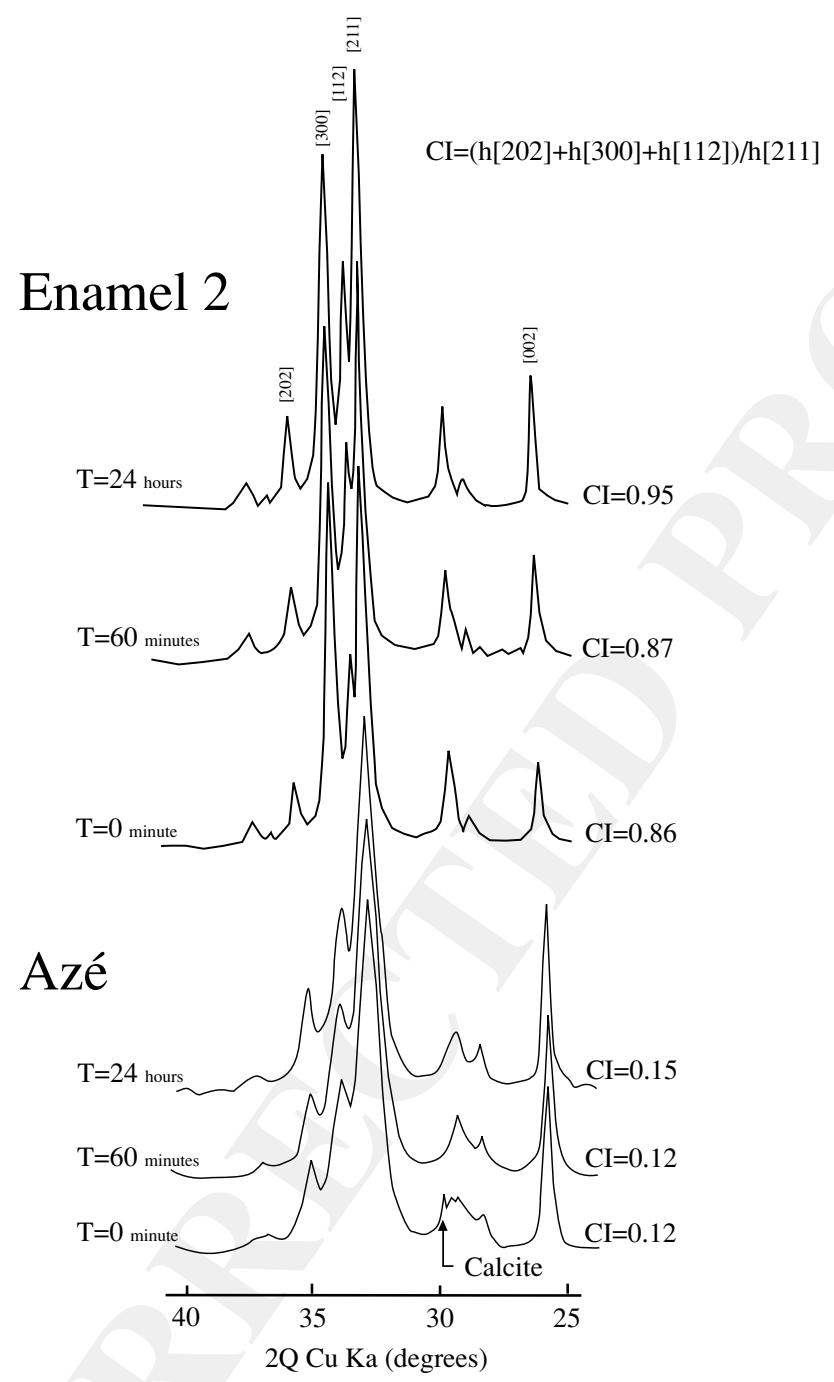

Figure 5 The evolution of the crystallinity of modern enamel (Enamel 2) and Azé samples. The crystallinity index (CI) was measured according to the Person et al. (1995) procedure.

duration of the reaction and thus minimizes contact of the biological material with acid. The results show that, under dynamic vacuum, dissolution of Ca-bearing carbonates is achieved in $1 \mathrm{~h}$. Any long-lasting acid etching may lead to a modification of the isotopic oxygen integrity. This alteration is characterized by an isotopic enrichment. With the present method, as calcitic phases could be trapped and characterized, this opens up the possibility of assessing further environmental information through the study of these authigenic compounds (Karkanas et al. 2000).

\section{REFERENCES}

Burton, J. H., Price, T. D., and Middleton, W. D., 1999, Correlation of bone $\mathrm{Sr} / \mathrm{Ca}$ and $\mathrm{Ba} / \mathrm{Ca}$ due to biological purification of calcium, Journal of Archaeological Science, 26, 609-16. 
Carlson, S. J., 1990, Vertebrate dental structures, in Skeletal biomineralization: patterns, process and evolutionary trends, vol. 1 (ed. J. G. Carter), 531-56, Van Nostrand Reinhold, New York.

Faure, G., 1986, Principles of isotope geology, 2nd edn, John Wiley, New York.

Hedges, R. E. M., Lee-Thorp, J. A., and Tuross, N. C., 1995, Is tooth enamel carbonate a suitable material for radiocarbon dating? Radiocarbon, 37, 285-90.

Karkanas, P., Bar-Yosef, O., Goldberg, P., and Weiner, S., 2000, Diagenesis in Prehistoric caves: the use of minerals that form in situ to assess the completeness of the archaeological record, Journal of Archaeological Science, 27, 915-29.

Koch, P. L., Tuross, N., and Fogel, M. L., 1997, The effects of sample treatment and diagenesis on the isotopic integrity of carbonate in biogenic hydroxylapatite, Journal of Archaeological Science, 24, 417-29.

Kohn, M. J., Schoeninger, M. J., and Barker, W. W., 1999, Altered states: effects of diagenesis on fossil tooth chemistry, Geochimica et Cosmochimica Acta, 63, 2737-47.

Lambert, J. B., and Weydert-Homeyer, J. M., 1993, The fundamental relationship between ancient diet and the inorganic constituents of bone as derived from feeding experiments, Archaeometry, 35, 279-94.

Lee-Thorp, J. A., and van der Merwe, N. J., 1991, Aspects of the chemistry of modern and fossil biological apatites, Journal of Archaeological Science, 18, 343-54.

Longinelli, A., 1984, Oxygen isotopes in mammal bone phosphate: A new tool for paleohydrological and paleoclimatological research? Geochimica et Cosmochimica Acta, 48, 385-90.

MacFadden, B. J., Solounias, N., and Cerling, T. E., 1999, Ancients diets, ecology and extension of 5-million-year-old horses from Florida, Science, 283, 824-7.

Person, A., Bocherens, H., Saliège, J.-F., Paris, F., Zeitoun, V., and Gerard, M., 1995, Early diagenetic evolution of bone phosphate: an X-ray diffractometry analysis, Journal of Archaeological Science, 22, 211-21.

Price, T. D., Blitz, J., Burton, J., and Ezzo, J. A., 1992, Diagenesis in prehistoric bone: problems and solutions, Journal of Archaeological Science, 19, 513-29.

Saliège, J. F., Person, A., and Paris, F., 1995, Preservation of ${ }^{13} \mathrm{C} /{ }^{12} \mathrm{C}$ original ratio and ${ }^{14} \mathrm{C}$ dating of the mineral fraction of human bones from Saharan tombs, Journal of Archaeological Science, 22, 301-12.

Sillen, A., and LeGeros, R., 1991, Solubility profiles of synthetic apatites of modern and fossil bones, Journal of Archaeological Science, 18, 385-97.

Sponheimer, M., and Lee-Thorp, J. A., 1999, Isotopic evidence for the diet of an early hominid, Australopithecus africanus, Science, 283, 368-70.

van der Merwe, N. J., 1982, Carbon isotopes, photosynthesis and archaeology, American Scientist, 70, 596-606. 